Original Research Article

\title{
Assessment and evaluation of drug information services provided by drug information centre at a multispecialty hospital in Erode, Tamil Nadu, India
}

\author{
Krishnaveni K.*, Kameswaran R., Sumitha S. K., Achsah Susan Sajan
}

Department of Pharmacy

Practice, J.K.K Nattraja College

of Pharmacy, Kumarapalayam,

Tamil Nadu, India

Received: 25 July 2018

Accepted: 30 August 2018

*Correspondence to:

Dr. Krishnaveni K.,

Email: venidhiya@gmail.com

Copyright: (C) the author(s), publisher and licensee Medip Academy. This is an openaccess article distributed under the terms of the Creative Commons Attribution NonCommercial License, which permits unrestricted noncommercial use, distribution, and reproduction in any medium, provided the original work is properly cited.

\begin{abstract}
Background: To evaluate the performance of Drug Information Centre (DIC) in providing quality drug information services to the health care professionals. Methods: It was a prospective study carried out for a period of six months (JuneNovember 2017). The drug information services provided by the pharmacist at the DIC during ward rounds, direct access, telephone and mail were documented in the drug information request and documentation forms. The quality of drug information provided was assessed with the help of feedback questionnaire which was filled by receivers.

Results: A total of 283 queries were received, with a maximum from ward rounds $140(49.47 \%)$. On evaluation, it was found that most of the queries were from physicians $207(73.14 \%)$ followed by nurses 33(11.66\%), pharmacists 26 $(9.18 \%)$, patients $17(6.07 \%)$. Among that $178(62.89 \%)$ queries were received from department of general medicine. Most of the queries were intended to update knowledge $110(38.86 \%)$ and for the purpose of better patient care $90(31.81 \%)$. The time frame for an authentic reply ranged from minutes to 24 hours, where a maximum of $110(38.86 \%)$ queries had sent a 24 hours deadline. The majority of the queries were for adverse drug reactions [ADR-60 (21.20\%)] and most preferred resources were primary $188(66.43 \%)$.

Conclusions: The DIC has always presented and offered itself to be an impressive resource, which is used routinely as an information source by all levels of professionals involved in the health system, in addition to the patients themselves.
\end{abstract}

Keywords: DIC, Drug information services, Drug resources, Health care professionals

\section{INTRODUCTION}

Drug information is the provision of written and/or verbal information or advice about drugs and drug therapy in response to a request from the health care providers, organizations, committees, patients or members of the public. ${ }^{1}$ These activities are undertaken especially by welltrained individuals i.e. Pharm. D graduates (Doctor of pharmacy) and Pharmacologists. In this decade more than 60,000 new formulations were coming into market with subsequent increase in number of adverse drug events. It is difficult to remember all the side effects and adverse drug reactions of all drugs to the health care professionals to monitor the patients. So clinical pharmacist has a key role to identify such adverse reactions and to assess, monitor them with help of physicians. ${ }^{2}$ Apart from that these professionals have more exposure with the patients, nurses, doctors and in all levels of health care professions so they could report newly detected case reports as well as signals to the world some time a rare and new unidentified adverse drug effect. Because of the constant and continuous interactions with the patients they could able to give proper patient education which will leads to increase medication adherence. In the busy schedule of the doctors 
hectic daily life sometime update of drug details may hinder, in such conditions dug information centre play a pivotal role in updating new drug information like withdrawal of drug from market, clinical research phases of developing drug molecule [i.e. investigational new drug and abbreviated new drug (IND, AND)], off label use and black box warning of drugs etc. The use of drugs in the society is widespread and therefore information on their safety, appropriateness and efficacy is necessary. ${ }^{3}$ Lack of unbiased drug information and lack of time are some of the factors that makes the physicians unable to update their knowledge about drugs which have resulted in an increasing demand for independent and unbiased information about drugs for better patient care. ${ }^{4,5}$ The way to decide which drug is best for formulary addition, is to rationally evaluate all aspects of scientific information in relation to similar agents. ${ }^{6,7}$ Not only in developing drug formulary but also for implementing rational therapy influence of DIC is appreciable. The centre focuses on providing unbiased drug information, well referenced, critically evaluated and up to date information which promotes safe and effective use of medication. ${ }^{8}$

Most of the developing countries suffer from lack of drug information due to limited availability of current literatures, authenticated open access databases, under reporting and poor documentation of drug related problems especially adverse events (AEs). After developing drug information centres in various parts of India clinical pharmacists can directly involve in the patient care by making numerous interventions, decreasing the medication errors and improve the patient compliance. ${ }^{2}$

WHO recognises independent drug information centres, as a core component of national programs to promote the rational use of medicines. The services should include collecting, reviewing, evaluating, indexing and distributing information on drugs to health workers. This allows access to clinical experiences, libraries, research facilities and educational activities. ${ }^{9}$

Thus, the aim of the present study was to evaluate the performance of drug information centre in providing quality drug information services to the health care professionals by clinical pharmacists. The services evaluated includes-collecting, reviewing, evaluating, indexing and distributing information on drugs to health workers.

\section{METHODS}

It was a prospective study carried out for a period of six months (November 2017 to April 2018). The drug information services provided by the pharmacist at the DIC during ward rounds, direct access, telephone and mail were documented in the drug information request and documentation forms, which were prepared by the department of DIC staffs. Our centre was well equipped with the trained staffs and Pharm.D interns and a library consisting of textbooks, national and international journals, computer with internet facility with an electronic database i.e. micromedex, genebrandex. Drug information was provided by using the three sources like primary sources, secondary sources and tertiary sources and services were provided between 8 am to $5 \mathrm{pm}$ in week days except in Sunday and government holidays. The drug information queries were evaluated, and answers were provided according to the modified systematic approach. The drug information requests and answers were documented and maintained in the drug information documentation files of the department. These services were free of cost and voluntarily provided for the aim of better patient care. These forms were evaluated prospectively on various parameters like speciality, status of enquirer, purpose of the enquiry, mode of request and question category, source of information (primary sources, secondary sources, and tertiary sources) time taken for providing information etc. All most all queries were answered within the requested time limit. Microsoft access was used for electronic documentation. The quality of drug information provided was assessed by receivers and providers, using feedback questionnaire.

\section{RESULTS}

A total of 283 queries were received and evaluated. Table 1 shows the assessment of drug information services provide by the DIC. 283 queries received with a maximum from ward rounds $140(49.47 \%)$.

It was found that most of the queries were from physicians $207(73.14 \%)$ followed by nurses $33(11.66 \%)$, pharmacists $26(9.18 \%)$, patients $17(6.07 \%)$.

Among that $178(62.89 \%)$ queries were received from department of general medicine. Most of the queries were intended to update knowledge $110(38.86 \%)$ and for the purpose of better patient care 90 (31.81\%).

The time frame for an authentic reply ranged from minutes to 24 hours, where a maximum of $110(38.86 \%)$ queries had sent a 24 hours deadline. and most preferred resources were primary $188(66.43 \%)$.

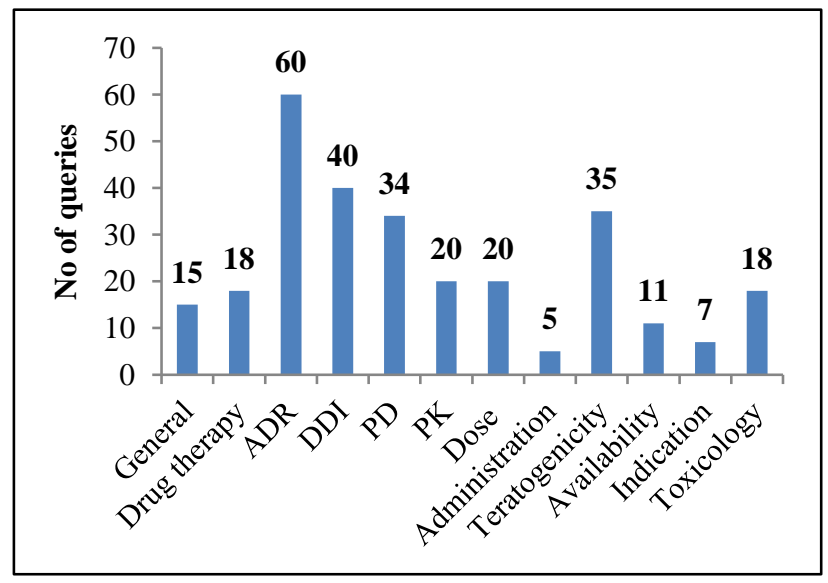

Figure 1: Information category. 
Figure 1 shows the information category related to query and majority of the queries were for adverse drug reactions [ADR-60 (21.20\%)].

Table 1: Assessment of drug information service provided by DIC.

\begin{tabular}{|c|c|c|}
\hline Query & $\begin{array}{l}\text { No. of queries } \\
(n=283)\end{array}$ & Percentage \\
\hline \multicolumn{3}{|c|}{ Medical speciality of enquirer } \\
\hline General Medicine & 178 & $62.89 \%$ \\
\hline General surgery & 08 & $2.82 \%$ \\
\hline $\begin{array}{l}\text { Obstetrics \& } \\
\text { gynaecology }\end{array}$ & 26 & $9.18 \%$ \\
\hline Orthopaedics & 15 & $5.3 \%$ \\
\hline Paediatrics & 18 & $6.36 \%$ \\
\hline Infectious & 13 & $4.59 \%$ \\
\hline Others & 25 & $8.83 \%$ \\
\hline \multicolumn{3}{|l|}{ Purpose of enquiry } \\
\hline Academic & 80 & $28.26 \%$ \\
\hline Patient care & 90 & $31.81 \%$ \\
\hline To update knowledge & 110 & $38.86 \%$ \\
\hline Others & 03 & $1.06 \%$ \\
\hline \multicolumn{3}{|l|}{ Mode of request } \\
\hline Direct access & 40 & $14.13 \%$ \\
\hline During ward round & 140 & $49.47 \%$ \\
\hline Telephone & 33 & $11.66 \%$ \\
\hline Email & 70 & $24.73 \%$ \\
\hline \multicolumn{3}{|c|}{ Time frame to reply the queries } \\
\hline Immediately & 35 & $12.36 \%$ \\
\hline 30-60 minutes & 90 & $31.81 \%$ \\
\hline Within a day & 110 & $38.86 \%$ \\
\hline Within 2 day & 40 & $14.13 \%$ \\
\hline Within a week & 08 & $2.82 \%$ \\
\hline \multicolumn{3}{|l|}{ Query receive from } \\
\hline Physician & 207 & $73.14 \%$ \\
\hline Nurses & 33 & $11.66 \%$ \\
\hline Pharmacist & 26 & $9.18 \%$ \\
\hline Patient & 17 & $6.07 \%$ \\
\hline \multicolumn{3}{|c|}{ Sources used for answering queries } \\
\hline Primary sources & 188 & $66.43 \%$ \\
\hline Secondary sources & 78 & $27.56 \%$ \\
\hline Tertiary sources & 17 & $6.07 \%$ \\
\hline \multicolumn{3}{|l|}{ Mode of reply } \\
\hline Verbal & 19 & $6.71 \%$ \\
\hline Written & 29 & $10.24 \%$ \\
\hline Printed & 165 & $58.30 \%$ \\
\hline Electronics & 70 & $24.73 \%$ \\
\hline
\end{tabular}

\section{DISCUSSION}

Drug information centre provide services to all the departments of the hospital and to all healthcare professionals. A total of 283 queries were received, with a maximum from ward rounds $140(49.47 \%)$ during the six month period. On evaluation of Table 1 , it was found that most of the queries were received from department of general medicine $178(62.89 \%)$ similar study results were obtained by Jeevangi VM et al, of nine months periods. ${ }^{10} \mathrm{It}$ may be because of co-operation of physicians in this department, because general physicians are dealing with the patients with multiple diseases and there is a maximum utilization of drugs and they need more information regarding drugs to update their knowledge. Majority of queries were asked for the purpose to update their knowledge $110(38.86 \%)$ followed by patient care 90 $(31.81 \%)$ academic 80 (28.26 and others 3 (1.06\%). Enquirers identification showed most of the queries arises from physicians side-207 $(73.14 \%)$ followed by nurses 33 (11.66\%), pharmacists $26(9.18 \%)$ and patients $17(6.07 \%)$. Drug information queries were received during on regular ward rounds $140(49.47 \%)$ attended by the students of Pharm D, by mode of direct access, telephone, and mails. A previous literature which supports our study, conducted by George et al, for a period of twelve months, shows that maximum numbers of queries were received during ward rounds $(70.7 \%) .{ }^{11}$ Total of $110(38.82 \%)$ queries were answered within a day and only $8(2.82 \%)$ queries were took one week time. Almost all of the enquirers received the appropriate answer within an acceptable time. This shows that efficiency of DIC working staffs and dedication of Pharm. D interns made it fast. We depends mainly on primary sources 188(66.43\%) followed by secondary sources $78(27.56 \%)$ such as original research articles, ongoing clinical trial reports for the collection of information rather than secondary (pubmed, medline databases, cochrane library) and tertiary (textbooks, genebrandex, micromedex, drug monographs such as American hospital formulary services (AHFS), National Formulary (NF), drugs facts and comparison, United State Pharmacopeia, etc. $6.07 \%$ of information was provided by tertiary sources such as textbooks and websites, because of ease of retrieval of information from textbooks and ease of use of computers and internet and availability of recent and relevant information from them.

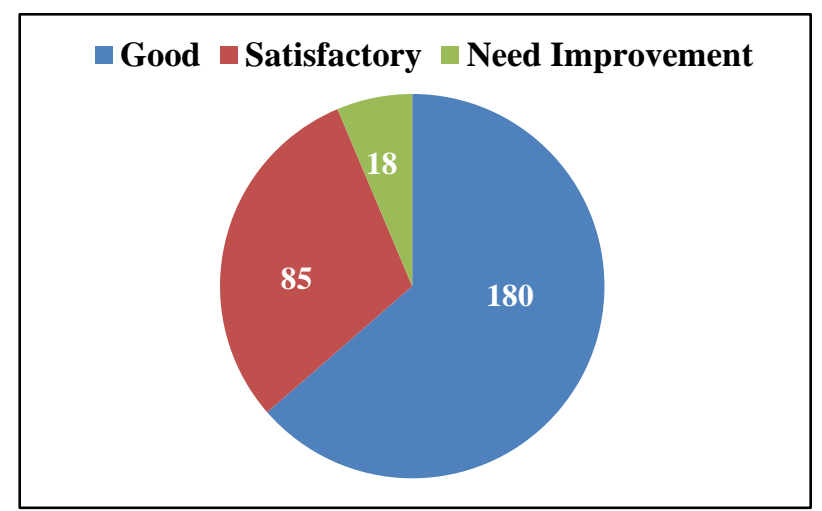

Figure 2: Feedback about query answering.

From Figure 1 it was found that majority of the queries were for adverse drug reactions [ADR-60 (21.20\%)] followed by $40 \%$ drug-drug interactions (DDI) and 35\% teratogenicity. But Mahendrakumar BJ et al, and Himanshu $\mathrm{P}$ et al, conducted a study showed that maximum numbers of queries were on dosage and administration. ${ }^{12,13}$ 
The quality of services provided by the DIC was appreciated by the health care professionals. About 180 $(63.60 \%)$ of the respondents rated the performance of the drug information centre as good, $85(30.03 \%)$ as satisfactory and $18(6.36 \%)$ suggested that the centre requires improvement in its services (Figure 2).

Some of the suggestions to improve the performance of the drug information centre were to provide information on recently approved drugs into the market and to extend the drug information services. The overall performance of the drug information centre was found to be good and this shows that the centre is maintaining its quality of service.

\section{CONCLUSION}

Drug information services provided by the department of Pharmacy Practice, were useful and beneficial to the health care professionals in providing better patient care and for updating their knowledge. There is a need to bring greater awareness about DIC in hospitals in and around DIC and to encourage the health care professionals to utilize the services for better patient care. The DIC has always presented and offered itself to be an impressive resource, which is used routinely as an information source by all levels of professionals involved in the health system, in addition to the patients themselves. Government and private hospitals should take measures to establish DIC in order to provide patient-focused services through efficient DICs.

\section{ACKNOWLEDGEMENTS}

Authors would like to thank all the participants.

Funding: No funding sources Conflict of interest: None declared

Ethical approval: Not required

\section{REFERENCES}

1. Pradeep P, Varma AS, Mounika S, Durga GL, Kumar MP, Kumar MV, et al. Retrospective study to analyse and evaluate drug information query services provided by clinical pharmacisits at a tertiary care teaching hospital. Pharma Innovation. 2015;4(7,Part A):36.

2. Joshi P. Drug information services in teaching hospitals in developing countries. Indian J Pharmacol. 1998;30:1-5.

3. Omole MK. Drug information service: Lecture delivered at Mandatory Continuing Professional development programme organized by pharmacy council of Nigeria. 1998;4:1-7.

4. Rosenberg JM. Drug information centres future trends. Am J Hospital Pharmacy. 1983;40:1213-15.

5. Ramesh M, Parthasarathi G. Drug information-Role of pharmacist. Indian $\mathrm{J}$ Pharma Education. 2000;34(3):120-3.

6. Kasilo OJ, Nhachi CF. Recommendations for establishing a drug and toxicology information center in a developing country. Ann Pharmacotherapy. 1991;25:1379-83.

7. Smith S, Bottle R. Use of information services by drug information pharmacists. Pharma J. 1994;253(6810):499-501.

8. Kumar MM, Sowmya B, Dinesh R, Karthik M, Nagar AK, Yogananda R, et al. Evaluation of performance of drug Information center providing quality of information services to healthcare professionals in a tertiary care teaching hospital of south India. Innovations Pharm Pharmacotherapy. 2013;1(2):8190.

9. Sreekanth SK, Sreekanth D. Need and importance of drug information centres in Indian Hospital system. Int J Med Health Profession Res. 2015;2(1):9-16.

10. Jeevangi VM, Patil N, Geni AB, Hinchageri SS, Manjunath G, Shantveer H. Assessment and evaluation of drug information service provided by pharmacy practice department based on enquirer's perspective. IRJP. 2012;3(10):193-9.

11. George B, Rao PG. Assessment and evaluation of drug information services provided in a South Indian teaching hospital. Indian J Pharmacol. 2005 Sep 1;37(5):315.

12. Mahendra Kumar BJ, Sandeep A, Krishnagoudar BS, Ravi Venkappa K, Ramanath KV. Assessment and evaluation of drug information services provided by the clinical pharmacists in a rural tertiary care teaching hospital of south India. RJPS. 2011;1(1):26-31.

13. Patel H, Churi S, Gurumurthy P, Madhan R. Quality assurance of drug information service and drug therapy review provided by clinical pharmacists in an Indian teaching hospital. Indian J Pharma Pract. 2015 Jul;8(3):117.

Cite this article as: Krishnaveni $\mathrm{K}$, Kameswaran $\mathrm{R}$, Sumitha SK, Sajan AS. Assessment and evaluation of drug information services provided by drug information centre at a multispeciality hospital in Erode, Tamil Nadu, India. Int J Basic Clin Pharmacol 2018;7:1987-90. 